\title{
The Role of Dialogic Organisation in Reflexive Construals of Identity in Selected Fiction Texts ${ }^{1}$
}

\section{Klára Matuchová}

This paper discusses the construals of personal/social identity as they appear in the communicative transactions of three protagonists of novels. In my use of the term, reflexive construal represents both the act of shaping and interpreting identity while it is still in progress within an ongoing communicative event. Herein, denotational/ referential and interactional success (see Agha 2007) are two discrete phenomena whose co-occurrence is realised through the dynamism of differing degrees of referential appropriateness and semiotic effectiveness that are in a relation of reciprocal proportion. I attempt to outline a semiotically mediated model of social role inhabitance, focusing on two types of dialogue as the key linguistic factor correlating with the occurrence of varieties of social personae in the process of identity negotiation. These varieties are the representations of the protagonists' potential social authenticities within the framework of fictional texts. My data seem to suggest that communicative dynamism in its textually extended pattern is maintained by the interdependence between the dialogue organisation and message structure. Alteration to the typical pattern of the former will result in alteration in the pattern of the latter, while maintaining the basic principle of distribution of degrees of communicative dynamism among the elements of these organisation types.

\section{Introduction}

Although personal and social identities function as inseparable entities, there is an underlying difference in their recognition that seems to be particularly clearly accentuated in late modernity. The reason is described by Taylor (1991) as follows:

Social recognition was built in to the socially derived identity from the very fact that it was based on social categories everyone took for granted. The thing about inwardly derived, personal, original identity is that it doesn't 


\section{KLÁRA MATUCHOVÁ}

enjoy this recognition a priori. It has to win it through exchange, and it can fail. What has come about with the modern age is not the need for recognition but the conditions in which this can fail. And that is why the need is now acknowledged for the first time. (47)

In practical terms, this change of conditions can be observed in British society in the form of a gradual loss of a rigidly-structured class hierarchy, which is seen by some as one of the principal social and attitudinal changes since the last coronation. In this context, identity as such is defined by Taylor (2000) as a firm horizon within which we can try to "determine from case to case what is good, or valuable" and are "capable of taking a stand" (27).

This paper has a general focus on the role of participation of language functions in identity negotiation in fiction discourse. Identity, in my use of the term, is best described by the attribute personal-social as I focus on the presentations of emergent inwardly derived personal identities by individual protagonists within the framework of socially derived pre-established identities. The three novels I analyze are John Braine's Room at the Top (further on as RT), Stephen Fry's The Stars' Tennis Balls (STB) and Alan Hollinghurst's The Line of Beauty (LB). Specifically, the RT protagonist Joe Lampton speaks his own voice, as he is presented throughout the novel in a first-person narrative. The LB protagonist Nick Guest is presented by an omniscient narrator in the third person. The most narratively complex presentation is substantiated by the character of Ashley Barson-Garland (STB), whose author's presentation strategy is two-fold: firstly, it is a third-person narration by Ashley's classmate or the omniscient narrator (example 3), and secondly, it is the protagonist's personal diary (example 4), in which he addresses himself from the perspective of an alter-ego initially in the second person, later alternated with a firstperson narration.

The following extracts illustrate the typical narrative types in the three novels, respectively:

(1) And I was wearing my shirt for the second day. I had the working-class mentality; anything was good enough for work (Braine 151).

(2) Nick had no brothers or sisters but he was able to think of himself here as a lost middle child. It was Toby who had brought him here [...] for his London 'seasons', long thrilling escapes from his own far less glamorous family... Toby himself had never perhaps known why he and Nick were friends, but had amiably accepted the evidence that they were. In these months after Oxford he was rarely there, 
and Nick had been passed on as a friend to his little sister and to their hospitable parents. He was a friend of the family; and there was something about him they trusted, a gravity, a certain shy polish, something not quite apparent to Nick himself, which had helped the family agree that he should become their lodger. (Hollinghurst 4-5)

(3) Ashley moved the four piles to the left of the blotter, a more convenient position for signing for when Sir Charles arrived. He was the perfect servant, intelligent, thoughtful, thorough and discreet and for the moment, this contented him (Fry $64)$.

(4) How did the Terrible Mistake happen? The terrible series of mistakes. How could your consciousness be the issue of his commonplace seed and her dull egg? Birth was the first terrible mistake. [...] In a previous incarnation you were one of them and now a trace memory lingers to torture you. You are a foundling perhaps, of the bastard by-blow of a ducal indiscretion, farmed off on these woeful people you are obliged to call your parents. (Fry 25-26)

The reason these particular novels were chosen is, primarily, the main motivation of the protagonists to rise in the social class hierarchy (see section 2 below). Secondarily, it is the different narrative approaches and also the fact that RT was published in and deals with the post-war era, while STB and LB offer a contemporary view of the social class in the times of Thatcherism and the England, respectively London, of the 1980s (see Chalupský 2008).

Although I subscribe to the view advocated by Fowler that texts are interactions rather than objects and dynamic discourses rather than formal language structures, it is important to emphasise that I do not view the novel characters' self-presentation as self-contained indicators of English nativespeakers' identity construction.

My aim is to contribute to the immensely diverse picture of how the written versions of personal experience reflect the socio-cultural realities of the English. Significantly, the advantage that fiction texts represent in comparison with spoken discourse is the fact that they offer a condensed model of behaviour, both linguistic and non-linguistic, enabling the analysis of realms of communication unreachable in real life situations. I believe that analytical approaches developed in these relatively more stable conditions can be consequently applied to other types of communication.

Herein, I focus specifically on the role of dialogue type in the reflexive construals of personal and social identity. The reflexive nature of these communicative processes is informed not only by the active role of both the 


\section{KLÁRA MATUCHOVÁ}

producer and the recipient, but equally, by the indelible role of the reader and analyst. In my description of the analysed discourse, the two types of dialogue I identify are internal and external. In accordance with Bakhtin's (2008) view that meaningfully used language is always represented by some form of dialogue, the internal type is primarily characterised by the speaker being their own addressee, while the implied reader (Iser 1974) with their "horizon of expectations" (Jauss 23) is the omnipresent recipient as well (see example 5 below), and the external by the communicative presence of at least two different interlocutors (see example 6 below). I approach dialogue not as essentially others-oriented linguistic behaviour but rather, as Coupland describes, "the outcome of a speaker's negotiation with him- or herself, as well as with actual or potential hearers - negotiation about what is sayable and interpretable at any particular discursive moment" (Coupland 423, emphasis mine).

(5) [...] he was following the odd working-class fashion, which seemed to me now, after Alice's tuition, as queer as going out without trousers. I felt a mean complacency; with that solid mass of brilliantined hair and mass-produced face..., the face enjoying itself at Blackpool with an open-necked shirt spread out over its jacket ... he'd never have the chance of enjoying a woman like Susan... (Braine 153)

(6) 'Very good of you to join us, Mr Barson-Garland,' said Sir Charles, shaking my hand in courtly style. 'How absurd of me, I can't keep calling you that. Ned hasn't told me your Christian name.'

'Ashley, sir,' I said, as Ned buried himself in confusion and the menu. (Fry 69)

\section{Identity vs. Alterity in Fiction Texts}

To introduce the aforementioned protagonists from a standpoint foregrounded in the respective novels, Joe Lampton (RT) is a working-class civil servant, who later marries into a factory owner's upper middle-class family. Ashley Barson-Garland (STB) is a lower middle-class college student and a political researcher, later becoming an MP, and Nick Guest (LB) is also a lower middleclass college student who later becomes a magazine editor and a lover of an upper-class partner. Therefore, the driving force behind these characters is their upward social mobility. Thus, their identity is constructed and negotiated in the context of suppressing the original identity and appropriating the new desired identity. Rather logically, making them lodge with the more socially privileged is a narrative framework all three authors employ. 
Hence, the non-aligned status characterising their class membership is inherent in all their self-presentations. As the protagonists' primary motivation is attaining a particular semiotic effect instead of presenting identity that is actually felt to be true, most of the self-presentations can be expected to be rather acts of alterity than identity. This term, originally used by Hastings and Manning (2004) in the context of reciprocally conscious negotiation of mock identities, is applied herein with two alterations. In my use of this concept, the degree of recipient awareness of mock identity negotiation is minimal, if not altogether absent. Moreover, the alter-identity is not constructed as mock in order to temporarily entertain but to realise a long-term desire.

Thus, as previously discussed elsewhere (Matuchová 2011), an act of alterity in the context of my current analysis should be understood within the dichotomy desired - actual, i.e., alterity as an expression of a desired identity disguised and, more importantly, perceived as an actual identity. Thus, the reflexive aspect of these identity construals is brought to the forefront, as the responsibility for meaning is "delegated" to the recipient and the fulfilment of the original communicative intention is contingent on its recognition and acknowledgement by the interlocutor (see also mechanism of negotiability in Leech 23).

Regardless of a specific context, there is a tendency for self-presentation in alterity negotiation to be pre-planned or rehearsed, unlike in identity negotiation proper where the facts are more readily available, since they are well-established about and for the speaker. Thus we could say that dialogic patterns pertaining to alterity presentation display features of reported speech - facts are not used to truthfully, i.e., in the sense of denotational/ referential appropriateness, express reality but to re-signify it within a new context by the means of accessory participation of a language function in opposition to the dominant one, e.g., the referential and the affective function (see Jakobson 1960).

\section{Material}

The original discourse of the novels was selectively reduced to sections pertaining to identity negotiation and these extracts were sampled into messages (see below). The following extract illustrates the initial stage of the proposed discourse analysis with the "identity" text highlighted in bold: 
(7) Then I rejected it. Not on moral grounds; but because I felt then, and still do, that envy's a small and squalid vice - the convict sulking because a fellow-prisoner's been given a bigger helping of skilly. This didn't abate the fierceness of my longing. I wanted an Aston-Martin, I wanted a three-guinea linen shirt, I wanted a girl with a Riviera suntan - these were my rights, I felt, a signed and sealed legacy.

As I watched the tail-end of the Aston-Martin with its shiny new G.B. plate go out of sight I remembered the second-hand Austin Seven which the Efficient Zombie, [...], had just treated himself to. (Braine 29)

Thus, a message is a particular extract of text related to the topic of identity negotiation always including the protagonist as a participant of either an internal or external dialogue. It follows that one of the main criteria for the delimitation of the text unit relevant for the current analysis is the retrievability of the hypertheme of identity based on key words explicitly or, for that matter, implicitly present. Hence, key words play the role of "items of special interest" (Firbas 29). Moreover, the message can be specifically defined within the process model of language (Leech 58-61) as an element of a three-part hierarchy of discourse - message - text.

Furthermore, thus determined textual units were divided into textual and spatial identity messages and within the former categorised into four groups according to the pertinent social variables they refer to. The reference was identified based on the presence of key words (loci) and the actual variable sets are the Presentation, Origin, Accent and Social System Set (see Table 1, 2 and 3 below). As to the variables, the Presentation Set includes primarily those of age, education and occupation; the Origin Set comprises family and geographical background; the Accent Set represents dispreferred and preferred types of pronunciation; the Social System Set class membership reference, comments and relevant attitudes. Lastly, the Setting Set refers to all the occurring issues of spatial identity in the novel.

The most significant distinction, however, is to be observed between the occurrence of internal, and external dialogue within textual identity, which has a considerable impact on the retrieved data. In Table 1 below for RT, the internal dialogue represents $80 \%$ of the relevant analysed discourse and the external $20 \%$ of the analysed discourse. In Table 2 for SB, the results are similar, with $74 \%$ of the internal dialogue occurrence and $26 \%$ of the external one. In Table 3 for LB, the results are the most balanced, with $47 \%$ of the internal and $43 \%$ of the external dialogue occurrence. 
Moreover, the values highlighted in grey represent the most marked topic choices within the respective narrative contexts. As Joe (RT) interacts mainly with strangers at first, hence the distributional pattern of the internal and external Presentation Set occurs. Out of the three protagonists, it is he who experiences the unfairness of the social class stratification the most poignantly. However, in his position it would be undesirable to admit his indignation explicitly, i.e., in an external dialogue, which is represented by the Social System values. Similarly for Ashley (SB), the social class system is mainly discussed in his private diary rather than in an external dialogue. As to the Accent Set, Ashley often explicitly comments on the used accent in his conversations with others (20\% in external dialogue as opposed to $9 \%$ in internal). Eventually, Nick (LB) focuses on the role of accent with intensity similar to Ashley. Furthermore, the Presentation Set (see Table 3) displays the highest occurring internal-external dialogue difference. As Nick spends most of his narrative time with his second family, the need for external selfpresentation does not arise frequently. However, as his character develops, he keeps re-defining his role in the internal dialogue form.

Table 1: Representation of Variable Sets in Room at the Top

\begin{tabular}{|l|r|r|}
\hline Variable Set & Internal Dialogue (80\%) & External Dialogue (20\%) \\
\hline Presentation & $24 \%$ & $47 \%$ \\
\hline Origin & $15 \%$ & $18 \%$ \\
\hline Accent & $15 \%$ & $23 \%$ \\
\hline Social System & $46 \%$ & $12 \%$ \\
\hline Total & $100 \%$ & $100 \%$ \\
\hline
\end{tabular}

Table 2: Representation of Variable Sets in The Stars' Tennis Balls

\begin{tabular}{|l|r|r|}
\hline Variable Set & Internal Dialogue (74\%) & External Dialogue (26\%) \\
\hline Presentation & $47 \%$ & $47 \%$ \\
\hline Origin & $20 \%$ & $20 \%$ \\
\hline Accent & $9 \%$ & $20 \%$ \\
\hline Social System & $\mathbf{2 4 \%}$ & $13 \%$ \\
\hline Total & $100 \%$ & $100 \%$ \\
\hline
\end{tabular}


Table 3: Representation of Variable Sets in Line of Beauty

\begin{tabular}{|l|r|r|}
\hline Variable Set & Internal Dialogue (47\%) & External Dialogue (43\%) \\
\hline Presentation & $34 \%$ & $13 \%$ \\
\hline Origin & $16 \%$ & $20 \%$ \\
\hline Accent & $8 \%$ & $23 \%$ \\
\hline Social System & $42 \%$ & $44 \%$ \\
\hline Total & $100 \%$ & $100 \%$ \\
\hline
\end{tabular}

\section{Key Concepts and Definitions}

In the last few decades, in terms of sociolinguistic research (apart from other disciplines), identity in relation to language has been extensively researched. For the current discussion, however, as my topic is quite narrowly focused, two theoretical concepts seem to stand out as the most significant, namely Roman Jakobson's (1960) theory of the six basic functions of verbal communication and Asif Agha's (2007) discussion of reflexivity in human communication and reported speech.

Jakobson (1960) determines six constitutive factors which inform six different functions of language: addresser, message, addressee, context, code, and contact. Verbal messages can rarely serve only one of these functions; therefore there is a discernible hierarchy of functions in each language sample which is governed by the predominant function. Jakobson calls the "division of labour" between the individual functions participation. Following the logic of hierarchy, a certain function displays the leading participation in each message, while other functions display the accessory participation.

Given the context of the current analysis, the principal notion Agha's (2007) work presents is reflexivity. He emphasises that "the social effects mediated by speech are highly context-bound or indexical in character" (Agha 14). As a result, the relevance of reflexive activity lies in the fact that it is an activity in which we can typify perceivable signs (extra-linguistic and linguistic) by using communication. The communicative process thus grants speakers the potential to re-signify particular social indexical values in specific context through reflexivity, a notion of crucial descriptive importance when discussing the construction of identity. 
The schematic representation below depicts a communicative model and expounds my application of both Jakobson's and Agha's concepts in this analysis. The dynamic orientation of the elements of a communicative event towards a certain goal marked by arrows shows how the information potential of the message is realised by dominant and accessory language functions in a specific situation. The vertical denotational axis illustrates the semiotic relationship between a language sign and the extra-linguistic reality. The horizontal interactional axis signals the semiotic relationship between the author of a message and the recipient. The third important element is the temporal axis which stands for communication unfolding in time. The oscillation of the message structure takes place along this axis. The overall balance of expressive and factual content is dependent on the communicative aims and the efficiency with which they are attained.

Figure 1: Semiotic Relationships in Identity Negotiation (based on Agha 2007)

S I T U A T I O N A L

C O N T E X T

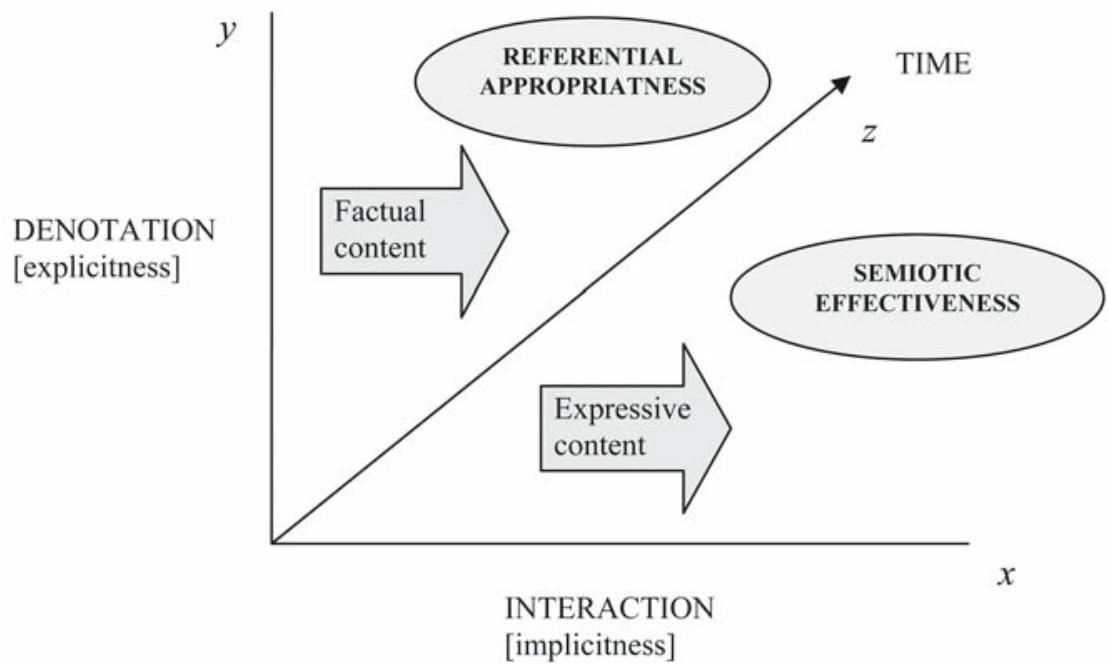




\section{KLÁRA MATUCHOVÁ}

In the framework discussed herein, the secondary theory I draw on is Functional Sentence Perspective (FSP) formulated by Firbas, derived from the concept introduced by Mathesius and developed throughout the $2 \mathrm{O}^{\text {th }}$ century by the Prague Linguistic Circle. The central notion is indicated by the term communicative dynamism:

It is an inherent quality of communication and manifests itself in constant development towards the attainment of a communicative goal [...]. Participating in this development, a linguistic element assumes some position in it and in accordance with this position displays a degree of communicative dynamism. [...] by a degree of communicative dynamism I understand the relative extent to which a linguistic element contributes towards the further development of the communication. (Firbas 7-8)

It follows that the most dynamic sentence elements will display the lowest context-dependence as they are imparting new information that is irretrievable from context. Conversely, the less dynamic elements are retrievable from context and therefore display a higher degree of context-dependence. In my application of the FSP theory I use a textually extended model that exploits messages as its elementary distributional fields, unlike the established FSP approach working with sentences/utterances. Herein, the communicative dynamism is maintained by the balance between specific linguistic features occurring in information structure and dialogue organisation. As this balance represents the key to the current analysis and as I am convinced theoretical concepts are best explained through practical application, I will provide more detailed comments below in the section introducing the research method (see 6.1. Information Structure of a Message).

\section{Hypothesis}

In the context of alterity negotiation, it should be emphasised that the semiotic effectiveness discussed herein can be seen as a form of attempted interpersonal domination which is rendered effective by the lack of recognition by the interlocutor. The advantage I see in using the term semiotic effectiveness rather than emotive language function or expressive content ( $c f$. Jakobson, 1960) lies in the fact that the necessity to distinguish between an expression 
of true or feigned attitude or emotion does not arise. In the analysed messages I primarily apply the distinction denotationally/referentially appropriate vs. semiotically effective. However, the presented framework does not discriminate against "facts" which are actually constructions of reality non-compliant with the verifiable truth conditions. The following examples illustrate this phenomenon (emphasis mine):

(8) “Well, sir. I live in Lancashire. I don't have any ..." Lancashire, indeed. I was used to saying that. Any 'shire' sounded better than Manchester. (Fry 70)

(9) 'Very few parents come to Speech Day,' I had written to her [his mother]. 'You'll find it a bore.' What I had meant was, 'Tou dare turn up and disgrace me in a bright print dress, cheap scent and a loathsome hat and I shall disown you.' (Fry 66-67)

Consequently, an expressed emotion or an attitude should be approached as a fact in its own right. The appropriate - effective distinction applies a posteriori in the process of verbalising identity/alterity and describes the message's content-in-process mainly in terms of its import (i.e., consequentiality) on the reader (if occurring in an internal dialogue) or on the recipient (if occurring in an external dialogue).

Thus, I base my hypothesis on the premise that the more appropriate, the less effective an act of communication will be (see Fig. 1 above). In my view, the effective refers primarily to interactionally successful, and the appropriate to denotationally correct (see Agha 2007) performance. Consequently, the more effective the content, the more implicit and indirect its expression will be, which should lead to deeper embeddedness of the key words in context (see also Matuchová 2008, 2009 and 2011).

If context embeddedness is considered an aspect of context-dependence, we can assert, based on the elementary tendencies of Functional Sentence Perspective ( $c f$. Firbas 1992), that when presenting given information its context-dependence will be relatively high, while its communicative dynamism relatively low. The reciprocal proportion will change accordingly in the case of new information being presented. By given information we can herein understand the loci of anticipatory messages, and, conversely, new information is typically represented by the loci of deferred messages (see below in 6.1.).

To relate the above hypothesis to the dialogic organisation in the analysed discourse, I presume the degree of semiotic effectiveness will be higher in 
external than internal dialogue. Therefore, the depth of context embeddedness can also be expected to be higher in the external dialogue information structure.

\section{Method}

\subsection{Information Structure of a Message}

For the analysis discussed herein, the key notion is the type of occurring dialogic organisation and its correlation with a particular information structure. The basic unit of analysis is a message that is a concrete realisation of a lexicogrammatical continuum, the ends of which are in a relationship of opposition and whose locus is represented by a key word. The semantic salience of these key words is displayed in different degrees depending specifically on the type of relation the key word enters with its lexico-semantic pair, thus creating either a contrastive or affirmative type of a message. Syntagmatically, the information structure of each message is best described by the linear position of the locus. If the locus appears in an initial position, the message type is called deferred, if in a closing position, it is called anticipatory.

Primarily, the information structure of a message can be analytically approached based on the type of paradigmatic and syntagmatic relation between the locus (i.e., the key word/-s), and its lexico-semantic pair that is present in every message. As is highlighted below in example 10 in capital letters, the pattern is carried by information nodes, which are the key words occurring in each sentence.

(10) 1/Suddenly, I had an INTUITION that I could sleep with Eva. 2/It was A GENUINE INTUITION, not simply A RATIONALISATION of my desires. 3/ I've always found that INTUITIONS are rarely wrong. 4/MINE work very well because I'm not very fond of abstract THINKING and I never expect anyone to be morally superior to myself. (Braine 33)

The basic unit of information structure in the above example is paradigmatically represented by the dichotomy intuition - thinking, i.e., two information nodes in a contrastive relationship, intuition being the locus. Syntagmatically, the salient feature of this message is the opening position of the locus, its relatively low embeddedness in the message context and the "cataphoric" reference from intuition to thinking, which occurs on three different textual levels. The 
primary (default) level delimits the information span of the whole message and is represented by thinking in sentence 4 and intuition in sentence 1 . The two secondary (immediate) levels are signalled by the same dichotomy obtaining between sentence 4 and 3 , and 4 and 2.

As demonstrated above, the term cataphora is henceforth used differently from the established concept of textual reference and cohesive ties (Halliday and Hasan 1976). Here, it is employed to indicate the presentation of new information that cannot be retrieved from the preceding context, and therefore the structure is deferred in relation to the locus place of occurrence. On the contrary, anaphorically oriented messages, i.e., displaying anticipatory structure, manifest the opposite direction of key information processing, with the locus occurring at the end of the message and the information nodes pointing forward towards it. The deferred type of information structure is illustrated by example 10 above.

\subsection{Depth of Context Embeddedness}

To quantify embeddedness, the information processing time can be indirectly calculated. Yet, the processing time is used only as a default factor as there is no explicit measurement involved. The formula that I use for calculation works with average node depth of context embeddedness $(A N D)$ while relating node clause length to message length and is based on Limburg (1986). However, this model can be successfully applied providing there is a certain degree of contrast between the adjacent nodes. It is calculated by assigning values to each message in the following manner:

- if message displays cataphoric orientation

- Node clause

$$
\begin{aligned}
& A=1(A=\text { locus }) \\
& B=2(B=\text { node referring to } A) \\
& C=3(C \text { node referring to } B) \\
& D=4(D=\text { node referring to } C)
\end{aligned}
$$

- if message displays anaphoric orientation

$$
\begin{array}{ll}
\text { Node clause } & \mathrm{D}=1(\mathrm{D}=\text { node referring to } \mathrm{C}) \\
\mathrm{C}=2(\mathrm{C}=\text { node referring to } \mathrm{B}) \\
\mathrm{B}=3(\mathrm{~B}=\text { node referring to } \mathrm{A}) \\
\mathrm{A}=4(\mathrm{~A}=\text { locus/key words })
\end{array}
$$

After values are assigned to all node clauses in a message, the values are added up and divided by the total number of node clauses in the message. Evidently, 
it takes longer to process B nodes than A nodes, longer to process $\mathrm{C}$ nodes than $\mathrm{B}$ nodes and so forth.

$$
\boldsymbol{A} \boldsymbol{N D}=\frac{\sum \mathcal{N} \text {-Values }}{\sum \mathcal{N} \text {-Clauses }}
$$

If a message had all A nodes, i.e., the information cluster would be absolutely homogenous with all nodes expressed by identical words or near-absolute synonyms, its average node depth $(A N D)$ would be 1.oo. Any number greater than 1.00 , such as 1.11 or 2.21 , indicates the percentage of time taken to process the information structure of a message, e.g., 1.11 indicates that 11 percent more time is required to process the message than if its value were 1.00 (also see Limburg 259). A practical illustration of the application of the formula is presented below (see example 10). Here, the information cluster is cataphorically oriented, i.e., a deferred type of message, the $A N D$ is 2.00 and the percentages express the node word span in each clause:

(11) A1 MY CLOTHES were my Sunday best: a light grey suit that had cost fourteen guineas, a plain grey tie, plain grey socks, and brown shoes $8 \%$.

B2 THE SHOES were THE MOST EXPENSIVE I'd ever possessed, with a deep, rich, nearly black lustre $31 \%$.

$C_{3}$ My trench-coat and my hat, though, weren't up to the same standard; THE COAT, after only three months, was BADLY WRINKLED and smelled of rubber, and THE HAT was FAINTLY DISCOLOURED with hair-oil and pinched to a sharp point in front 20\%. (Braine 7)

\section{Corpus Findings}

When compared with the hypothesis, my results confirm my expectations directly in the case of Room at the Top and The Line of Beauty, and indirectly in The Stars' Tennis Balls. In RT and LB, the external dialogue AND curve is consistently higher than the internal dialogue curve, which is indicative of information structure displaying greater depth of context embeddedness. Consequently, the degree of implicitness and indirectness should be higher in external dialogue as well. Figure 2 below presents the results for AND in The Line of Beauty with the lower curve illustrating internal dialogue and the 
higher curve symbolizing external dialogue. The vertical numerical values are the average node depth units, while the numbers on the horizontal axis stand for the variable sets listed above the graph.

Figure 2: Average Node Depth of Context Embeddedness in The Line of Beauty

( 1 = System, 2 = Setting, 3 = Origin, 4 = Presentation, 5 = Accent $)$

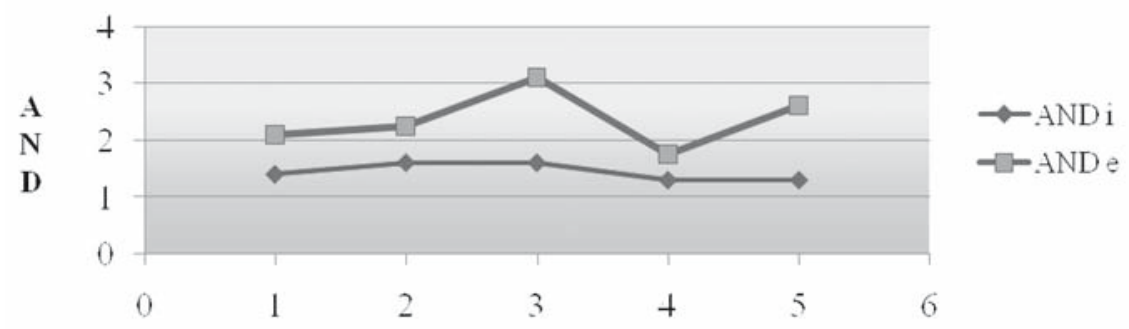

Variable Sets

The most significant differences are obtained between the AND values of the Origin and Accent Set, while the Presentation Set exhibits almost identical average values for both the internal and external curves. Referring to what I stated earlier about self-presentation in alterity negotiation, these results seem to confirm quite clearly the original assumption.

If we presume that self-presentation in alterity negotiation is typically preplanned or rehearsed in order to eliminate the impact of the lack of readily available personal facts that would be desirable and "presentable", we can expect such dialogic organisation to display features of reported speech. Practically, this means that facts are not used to truthfully express reality, i.e., in compliance with the given truth-conditions, but rather to re-signify it. Therefore, the Presentation Set results shown above should not be unexpected. The "reported speech" effect might not be as pervasive in this case, since out of all the other occurring variables these particular personal facts, i.e., name, age, education, occupation, are the most difficult ones to re-signify effectively.

Conversely, the most substantial differences occurring in the Origin Set, i.e., family and geographical background, might be indicative of a sufficient communicative potential for leaving the illocutionary force unclear and more implicit (hence, the higher degree of indirectness and greater context 


\section{KLÁRA MATUCHOVÁ}

embeddedness). Thus, the facts about the protagonist's origin are more easily re-signified, should the need arise in a new context with an unaware interlocutor. In example 11 below, such re-signification is referred to (emphasis mine):

(12) [...] when he told Leo that his father was an antiques dealer the two words, with the patina of old money and the flash of business, seemed to combine in a dull glare of privilege. Among his smart Oxford friends Nick managed to finesse his elbow-patched old man, with Volvo estate full of blanket-wrapped mirrors and Windsor chairs, into a more luminous figure, a scholar and friend of the local aristocracy. (Hollinghurst 33)

The quantitative data presented in Tables 1-3 above seem to influence the obtained context-embeddedness results directly only in terms of the internalexternal dialogue proportion. The respective distributional patterns of the variable set occurrence do not display any directly discernible quantitative correlation.

\section{Conclusions}

As was originally expected, my results confirm the hypothesis that the external dialogue organisation in the analysed discourse will display a higher degree of semiotic effectiveness than the internal dialogue organisation, containing more implicit information structures.

Regarding the relation between the dialogue organisation and information structure, there is a tendency for the external dialogue messages to display deferred information structure, i.e., locus presented as given information, more predominantly, which, assumingly, leads to higher AND values. However, the STB external dialogue displays lower AND values than the internal dialogue. The reason might be in the fact that the STB internal dialogue is mainly conducted in the form of diary entries serving the purpose of preparing or rehearsing the following external dialogue. STB is the only corpus in which the number of anticipatory messages, i.e., locus presented as new information, is lower in the internal than in the external dialogue. Also, in its external dialogue in all but one variable set the anticipatory messages do not occur whatsoever. 
My data seem to suggest that communicative dynamism is maintained by the interdependence between the dialogic organisation and information structure. Alteration to the typical pattern of the former will result in alteration in the pattern of the latter while maintaining the basic distribution of degrees of communicative dynamism among the elements of these organisational and structural patterns. The STB external dialogue is untypically focused on denotational/referential appropriateness rather than semiotic effectiveness, which is a considerable alteration to its dialogue organisation. Equally, the information structure of its external dialogue messages displays similar reversal of typical organisational disposition, i.e., a somewhat higher incidence of anticipatory messages than in the internal dialogue.

\section{Notes}

1. The present discussion is based, in parts, on three earlier papers by the same author, Matuchová 2008, 2009 and 2011.

\section{Works Cited \\ Primary Sources}

Braine, John. Room at the Top. 1957. Harmondsworth: Penguin Books, 1963. Fry, Stephen. The Stars' Tennis Balls. 2000. London: Arrow Books, 2001. Hollinghurst, Alan. The Line of Beauty. London: Picador, 2004.

\section{Secondary Sources}

Agha, Asif. Language and Social Relations. Cambridge: Cambridge University Press, 2007.

Bakhtin, Mikhail M. The Dialogic Imagination. Four Essays. 1975. Ed. Michael Holquist. Trans. Caryl Emerson and Michael Holquist. Austin: University of Texas Press, 2008.

Chalupský, Petr. “The City's Lines of Force - The Image of the City in Martin Amis's London Fields." Eds. Anna Grmelová, Libuše Dušková, Mark Farrell and Renata Pípalová. Plurality and Diversity in English Studies. Prague: Charles University, 2008. 151-159.

Coupland, Nicholas. "Sociolinguistic Authenticities." Journal of Sociolinguistics $7 \cdot 3$ (2003): 417-31.

Firbas, Jan. Functional Sentence Perspective in Written and Spoken Communication. Cambridge: Cambridge University Press, 1992.

Fowler, Roger. Linguistic Criticism. $2^{\text {nd }}$ edition. Oxford: Oxford University Press, 1996. 


\section{KLÁRA MATUCHOVÁ}

Halliday, Michael A. K. and Ruqaya Hasan. Cohesion in English. London and New York: Longman, 1976.

Hastings, Adi and Paul Manning. "Introduction: Acts of Alterity." Language and Communication 24.4 (2004): 291-311.

Iser, Wolfgang. The Implied Reader: Patterns of Communication in Prose Fiction from Bunyan to Beckett. Baltimore: The Johns Hopkins University Press, 1974 .

Jakobson, Roman. "Closing Statement: Linguistics and Poetics." Style in Language. Ed. Thomas A. Sebeok. Cambridge, Massachusetts: The M.I.T. Press, 1960. 350-77.

Jauss, Hans R. Literary History as a Challenge to Literary Theory. Toward an Aesthetic of Reception. Minneapolis: University of Minnesota Press, 1982.

Leech, Geoffrey N. Principles of Pragmatics. London: Longman, 1983.

Limburg, Kay B. "Quantitative Analyses of the Style of Woolf's Orlando." Language and Style 19.3 (1986): 250-79.

Mathesius, Vilém. Fazyk, kultura, slovesnost. Ed. Josef Vachek. Praha: Odeon, 1982.

Matuchová, Klára. "Meet the Lodger: Introducing Three Fictional Identities." Eds. Anna Grmelová, Libuše Dušková, Mark Farrell and Renata Pípalová. Plurality and Diversity in English Studies. Prague: Charles University, 2008. 92-100.

--. "Context Embeddedness as a Diacritic of Social Personae in Identity Negotiation." Ed. Irmgard Kolinská. Challenges in English Language Teaching III. Ústí nad Labem: Purkyně University, 2009. 23-33.

---. "Fur Coat, No Knickers: Semantic Potentiality in Alternative Identity Negotiation." Eds. Kathrin Kaufhold, Sharon McCulloch and Ana Tominc. Papers from the Lancaster University Postgraduate Conference in Linguistics and Language Teaching, Vol. 5. Lancaster: Lancaster University, 2011. 109-33.

Taylor, Charles. The Ethics of Authenticity. Cambridge, Massachusetts and London: Harvard University Press, 1991.

---. Sources of the Self. The Making of the Modern Identity. Cambridge: Cambridge University Press, 2000. 